\title{
IMPLEMENTASI PIRANTI JARINGAN REPEATER ECO VILLAGE MENGGUNAKAN MODEL PROTOTYPE DAN KONSEP GREEN COMPUTING
}

\author{
Ade Bastian $^{1}$, Arif Yusuf Budiman ${ }^{3}$ \\ Universitas Majalengka ${ }^{1}$, Universitas Majalengka ${ }^{2}$ \\ Jl. Universitas Majalengka No.1 Majalengka ${ }^{1}, \mathrm{Jl}$. Universitas Majalengka No.1 Majalengka ${ }^{2}$ \\ adb@ft.unma.ac.id ${ }^{1}$, arif_yusuf_budiman@yahoo.com ${ }^{2}$
}

\begin{abstract}
Abstrak
Internet sudah menjadi kebutuhan pokok bagi sebagian orang, ini dikarenakan dengan adanya internet manusia bisa mendapatkan informasi apapun yang diinginkan. Akses internet juga harus didukung dengan sinyal yang memadai, sehingga pengguna dapat leluasa mengakses internet kapanpun dan dimanapun. Khususnya dalam sebuah perkantoran sangat diperlukan sekali akses internet untuk menunjang kinerja pegawainya, namun tidak demikian dengan Kantor Kelurahan Majalengka Wetan. Minimnya jarak lingkup sinyal wireless pada Kantor Kelurahan Majalengka Wetan menjadi permasalahan serius. Para staf kesulitan dalam mendapatkan akses internet, ini dikarenakan hanya beberapa ruangan saja yang dapat akses internet. Penelitian ini bertujuan untuk mengetahui seberapa jauh jarak yang bisa dilalui sinyal wireless langsung di objek penelitian.Repeater merupakan sebuah piranti jaringan yang berfungsi untuk memperkuat dan memperpanjang jarak lingkup sinyal atau jaringan wireless. Dengan menggabungkan dengan komponen pengembangan, repeater dapat dibuat kembali menjadi piranti jaringan yang melebihi fungsi aslinya serta ramah lingkungan. Setelah dilakukan pengujian di objek penelitian maka diketahui jarak maksimum yang dapat dilalui sinyal wireless adalah $\pm 10 \mathrm{~m}$.
\end{abstract} Kata Kunci : Internet, Wireless, Repeater, Eco Village

\begin{abstract}
Internet has become a staple for some people, because with the internet people can get any desired information. Internet access should be supported with adequate signal, so user can freely access the internet anytime and anywhere. Especially in an office is very necessary the internet access to support the performance of employees, But not so with the East
\end{abstract}

Majalengka Village Office. The lack scope of wireless signal at the East Majalengka Village Office is a serious problem. Staff difficult to get internet access, this is because only a few rooms can access the internet. This study aims to find out how far distance can be directly wireless signal at East Majalengka Village Office.Repeater is a network deviceworks to strengthen and extend the scope of the signal wireless network. By combining with the development component, The repeater can be re-built into a network device that exceeds its original function and is environmentally friendly. After testing in the East Majalengka Village Office then known maximum distance signal wirelessis $\pm 10 \mathrm{~m}$.

Keywords : Internet, Wireless, Repeater, Eco Village

\section{Pendahuluan}

Seperti Dalam kehidupan kita, banyak kita temukan barang-barang yang terbuang begitu saja dikarenakan tidak ada manfaatnya lagi. Sehingga bahan - bahan yang tidak digunakan tersebut mencemari lingkungan sekitar kita, merusak ekosistem tanah karena sampah yang tidak bisa diuraikan oleh tanah. Pada saat sekarang ini sudah banyak kita lihat pemanfaatan barang/ bahan daur ulang yang menghasilkan barang/ bahan baru yang sangat memiliki nilai, bahkan dalam proses pemasaran juga memiliki harga yang cukup tinggi. Selain diproduksi untuk pemasaran dan menghasilkan uang, pemanfaatan barang/ bahan daur ulang ini juga bisa digunakan sebagai media pembelajaran. Karena barang-barang bekas tersebut bisa dimanfaatkan untuk media pembelajaran, seorang guru akan merasa lebih dimudahkan karena media pembelajaran tidak harus menggunakan alat-alat yang mahal dan sulit didapat sehingga proses pembelajaran akan berlangsung 
dengan efektif tanpa memberatkan salah satu pihak. [Novita, 2013]

Internet merupakan sebuah inovasi untuk mengolah informasi dan mendistribusikannya secara cepat. Memasuki era globalisasi yang bisa juga disebut dunia tanpa batas, informasi menjadi hal yang penting bahkan menjadi sebuah kebutuhan dalam menjalani hidup.Dengan masuknya internet ke daerah pedesaan, maka mayarakat dapat dengan cepat dan mudah mengakses informasi. Masyarakat tidak lagi menunggu informasi yang datang dari mulut ke mulut, karena akan memakan waktu lama dan kurang akurat mengingat media penyimpanannya adalah otak manusia.Daerah pedesaan juga sudah mengenal media massa seperti koran, majalah dan media elektronik seperti radio, televisi yang juga merupakan media penyampaian informasi. Akan tetapi dari media tersebut masyarakat menjadi pasif karena menerima informasi yang sudah disediakan media, sedangkan dengan internet mayarakat menjadi aktif karena bisa menentukan, mencari, kemudian mendapatkan informasi sesuai dengan kebutuhan. [Pramono, 2008]

Indonesia menghasilkan banyak sampah dalam seharinya. Sampah tersebut menjadi polusi bagi rakyat Indonesia mulai dari sampah yang mudah hancur pada tanah dan ada juga yang susah hancur pada tanah, sampah inilah yang membuat polusi di Indonesia. Sampah-sampah itu berupa plastic, pipet, besi, metal, tembaga dan baskom. Dari semua sampah tadi, kami memilih besi dan metal sebagai bahan utama proses pengabungan dengan piranti jaringan yang berguna yaitu berupa piranti jaringan repeater dengan menggunakan sampah berbahan baku besi/ metal. Dengan hasil pembuatan repeater tersebut akan dibuat untuk memperkuat dan memperluas jarak sinyal wifi di Kantor Kelurahan Majalengka Wetan. [Sasrawan, 2016]

Tabel 1. Persentase Sampah di Indonesia

\begin{tabular}{|l|r|r|}
\hline \multicolumn{1}{|c|}{ Jenis Sampah } & \multicolumn{1}{c|}{$\begin{array}{c}\text { Jumlah } \\
\text { (juta ton/tahun) }\end{array}$} & \multicolumn{1}{c|}{$\begin{array}{c}\text { Persentase } \\
\text { (\%) }\end{array}$} \\
\hline Sampah Dapur & 22,4 & $58 \%$ \\
\hline Sampah Plastik & 5,4 & $14 \%$ \\
\hline Sampah Kertas & 3,6 & $9 \%$ \\
\hline Sampah Lainnya & 2,3 & $6 \%$ \\
\hline Sampah Kayu & 1,4 & $4 \%$ \\
\hline Sampah Kaca & 0,7 & $2 \%$ \\
\hline Sampah Karet/Kulit & 0,7 & $2 \%$ \\
\hline Sampah Kain & 0,7 & $2 \%$ \\
\hline Sampah Metal & 0,7 & $2 \%$ \\
\hline Sampah Pasir & 0,5 & $1 \%$ \\
\hline TOTAL & 38,5 & $100 \%$ \\
\hline
\end{tabular}

Green IT atau Green Computing adalah studi dan pemanfaatan dari perancangan, pembuatan, penggunaan, dan pembuangan komputer, server, serta

Subsistem-seperti monitor, printer, perangkat penyimpanan, serta jaringan dan sistem komunikasisecara efisien dan efektif dengan dampak minimal atau bahkan tanpa dampak terhadap lingkungan. [Murgesan, 2008]

Repeater jaringan atau Network Repeater adalah perangkat yang digunakan untuk memperluas jaringan dari daerah jaringan kabel lokal (LAN) atau nirkabel (WiFi). Di masa lalu, repeater jaringan kabel yang digunakan untuk menggabungkan segmen Ethernet kabel.Repeater akan memperkuat sinyal data sebelum mengirimkan mereka ke segmen uplinked, sehingga sinyal dapat diperluas jangkauannya dari pada kawat. Jaringan Ethernet Modern menggunakan perangkat switching lebih yang canggih, menggantikan perangkat nirkabel dari repeater jaringan yang lebih populer untuk digunakan dengan LAN nirkabel (WLAN) di tempat kerja dan rumah.Repeater adalah suatu alat yang berfungsi memperluas jangkauan sinyal WIFI yang belum tercover oleh sinyal dari server agar bisa menangkap sinyal WIFI. Perangkat Repeater harus 2 alat, yakni untuk menerima sinyal dari server (CLIENT) dan untuk menyebarkan lagi sinyal Wifi (accespoint).Penjelasan diatas Dilansir dari wikipedia, Penguat Sinyal (inggrisnya=repeater) adalah sebuah perangkat elektronik yang menerima isyarat dan mentransmisikan kembali isyarat tersebut dengan daya yang lebih tinggi, sehingga isyarat tersebut dapat menjangkau area yang lebih luas. [Ardiyansyah, 2016]

Seperti yang telah diketahui bahwa penggunaan wireless di dunia ini sudah sangat banyak dijumpai dalam kehidupan sehari - hari kita, dengan adanya wireless kita tidak perlu pusing dengan masalah kabel yang berantakan, dengan adanya wireless ini di rumah, kantor, dan kampus. Wireless disebut nirkabel, adalah teknologi yang menghubungkan dua piranti untuk bertukar data atau suara tanpa menggunakan media kabel. Data dipertukarkan melalui media gelombang cahaya tertentu (seperti teknologi infra merah pada remote TV) atau gelombang radio (seperti bluetooth pada komputer dan ponsel) dengan frekuensi tertentu. Kelebihan teknologi ini adalah mengeliminasi penggunaan kabel, yang bisa cukup mengganggu secara estetika, dan juga kerumitan instalasi untuk menghubungkan lebih dari 2 piranti bersamaan. Kekurangan teknologi ini adalah kemungkinan interferensi terhadap sesama hubungan nirkabel pada 
piranti lainnya. Studi kasus yang saya temukan di Kelurahan Majalengka Wetan adalah hanya terdapat 1 access point yang memancarkan sinyal wirelesss yang telah terhubung dengan internet dan memiliki daya cakupan ruang yang terbatas, sehingga para staf kantor kelurahan yang tidak terjangkau oleh jaringan wireless harus pindah ke ruangan rapat untuk mendapatkan akses internet. Oleh karena itu diperlukannya sebuah media sebagai penguat sinyal wireless agar seluruh pegawai ke Kelurahan Majalengka Wetan mendapatkan akses internet.

\section{KaJian Pustaka}

\section{II.1 Green IT Policy}

Organisasi harus mengembangkan Green IT Policy yang selaras dengan kebijakan lingkungan secara keseluruhan. Green IT Policy meliputi kerangka organisasi yang ditempatkan untuk menerapkan kriteria lingkungan dalam kegiatan TI yang berhubungan. Hal ini mendefinisikan sejauh mana green issues yang dikemas dalam prosedur organisasi membimbing penggunaan, sumber dan pembuangan infrastruktur teknis TI, kegiatan infrastruktur TI, dan penggunaan TI di perusahaan yang lebih luas. [Murgesan, 2008]

Jatuh tempo Green IT Policy mencerminkan pertimbangan lingkungan secara sistematik menyerap value chain aktivitas TI dan secara berulang atau tidak teratur dan didasarkan pada upaya yang tidak terkoordinasi. Kebijakan (policy) membuat organisasi untuk melakukan Green IT. Namun, tidak semua policy diharapkan dapat dilaksanakan dengan lancar dan tidak semua praktik diharapkan menjadi policy.

Green IT Policy tidak hanya mengenai penggunaan TI di perusahaan tetapi juga dapat mencakup kebijakan mengenai pengelolaan setelah TI tidak dapat digunakan. Hal ini termasuk kebijakan mengenai pengelolaan e-waste salah satunya yaitu proses recycling. Proses recycling adalah proses daur ulang TI yang sudah tidak dapat digunakan. Green IT Policy proses recycling dapat menjadi panduan kebijakan recycling TI yang tidak dapat digunakan lagi di dalam suatu perusahaan dan melibatkan pihakpihak yang bersangkutan dalam melakukan recycling tersebut.
II.2 Siklus hidup Green Computer

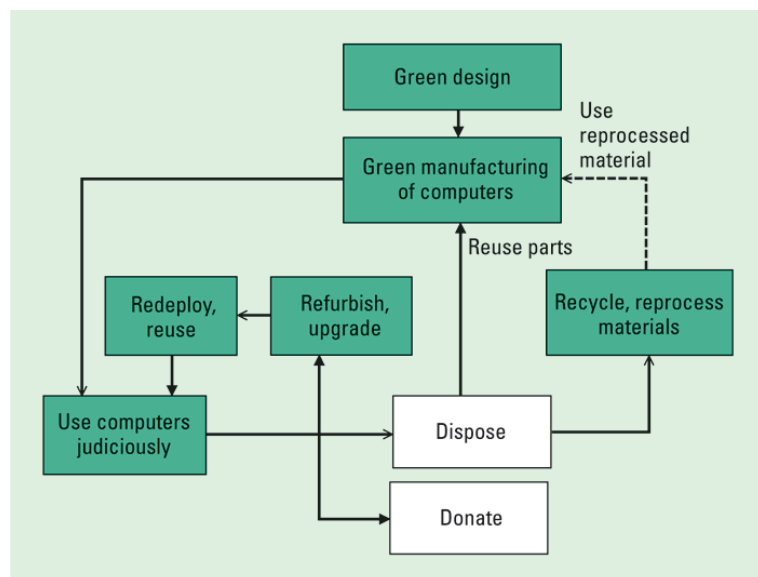

Gambar 1. Green Computer's Entire Life Cycle

Menurut Murugesan dan Gangadharan (2012, p8) seluruh siklus hidup dari komputer, server, storage system dapat dibuat lebih hijau, mengurangi emisi gas rumah kaca dan jejak karbon serta meminimalkan atau menghilangkan bahan beracun yang digunakan dan/atau dilepaskan ke lingkungan. [Murgesan, 2008]

\section{Metode Penelitian}

Sebuah prototipe adalah bagian dari produk yang mengekspresikan logika maupun fisik antarmuka eksternal yang ditampilkan. Konsumen potensial menggunakan prototipe dan menyediakan masukan untuk tim pengembang sebelum pengembangan skala besar dimulai. Melihat dan mempercayai menjadi hal yang diharapkan untuk dicapai dalam prototipe. Dengan menggunakan pendekatan ini, konsumen dan tim pengembang dapat mengklarifikasi kebutuhan dan interpretasi mereka. ${ }^{[\text {Pressman, 2008] }}$

Tahapan-tahapan dalam Prototyping adalah sebagai berikut:

a. Pengumpulan kebutuhan Pelanggan dan pengembang bersama-sama mendefinisikan format seluruh perangkat lunak, mengidentifikasikan semua kebutuhan, dan garis besar sistem yang akan dibuat.

b. Membangun prototyping Membangun prototyping dengan membuat perancangan sementara yang berfokus pada penyajian kepada pelanggan (misalnya dengan membuat input dan format output); 
c. Evaluasi protoptyping Evaluasi ini dilakukan oleh pelanggan apakah prototyping yang sudah dibangun sudah sesuai dengan keinginan pelanggan. Jika sudah sesuai maka langkah 4 akan diambil. Jika tidak prototyping direvisi dengan mengulang langkah 1, 2, dan 3;

d. Mengkodekan sistem Dalam tahap ini prototyping yang sudah di sepakati diterjemahkan ke dalam bahasa pemrograman yang sesuai;

e. Menguji sistem Setelah sistem sudah menjadi suatu perangkat lunak yang siap pakai, harus dites dahulu sebelum digunakan. Pengujian ini dilakukan dengan White Box, Black Box, Basis Path, pengujian arsitektur dan lain-lain;

f. Evaluasi Sistem Pelanggan mengevaluasi apakah sistem yang sudah jadi sudah sesuai dengan yang diharapkan. Jika ya, langkah 7 dilakukan; jika tidak, ulangi langkah 4 dan 5;

g. Menggunakan sistem Perangkat lunak yang telah diuji dan diterima pelanggan siap untuk digunakan.

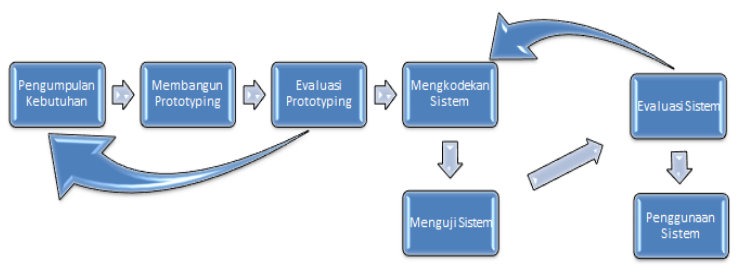

Gambar 2. Alur Model Prototype

\section{IMPLEMENTASI}

Dalam melakukan pengujian piranti jaringan komputer dilakukan 2 langkah dalam melakukan pengujian, yaitu dengan cara pengujian hardware dan pengujian software.

a. Pengujian Hardware

1) Mengecek apakah kabel USB Extender sudah terhubung dengan adapter power;

2) Perhatikan apakah adapter power sudah menerima arus listrik;

3) Perhatikan indikator lampu repeater jika berwarna kuning menandakan repeater masih mencoba menghubungkan dengan sinyal wirelles modem, jika sudah berwarna biru maka repeater siap digunakan;

4) Perhatikan sinyal bar wirelles minimal harus memiliki 1bar sinyal agar dapat diperkuat sinyalnya;
5) Jarak terjauh agar repeater dapat memperkuat sinyal wirelles adalah sejauh $\pm 10 \mathrm{~m}$.

6) Repeater dapat terus hidup dan terhubung pada jaringan selama sinyal wireless yang diperkuat tidak mati atau menghilang.

\section{b. Pengujian Software}

Software yang digunakan dalam pengujian piranti jaringan repeater adalah menggunakan software WirellesMoon (Wirelles Monitoring) dan diuji langsung di Kantor Kelurahan Majalengka Wetan. Berikut hasil dari pengujian software yang dilakukan :

1) Pengujian sinyal wirelles pada jarak $0 \mathrm{~m}-3 \mathrm{~m}$

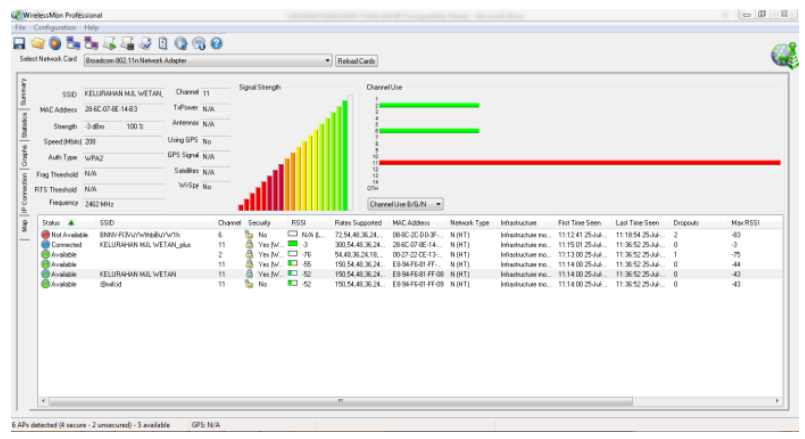

Gambar 3. Tab Summary (0m-3m)

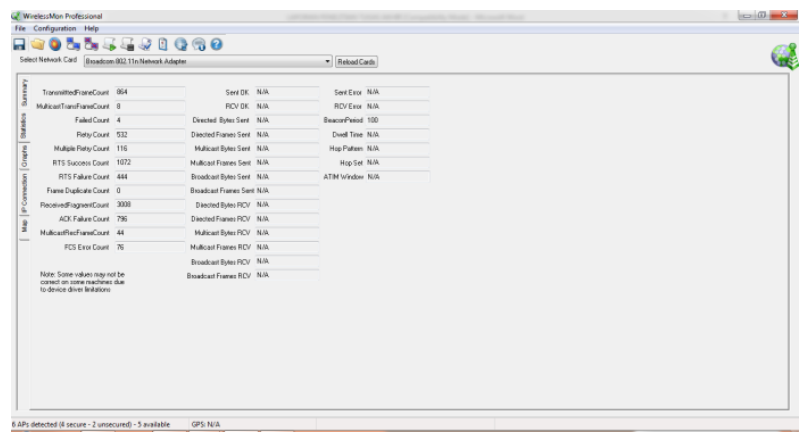

Gambar 4. Tab Static (0m-3m) 


\section{(2) UTama}

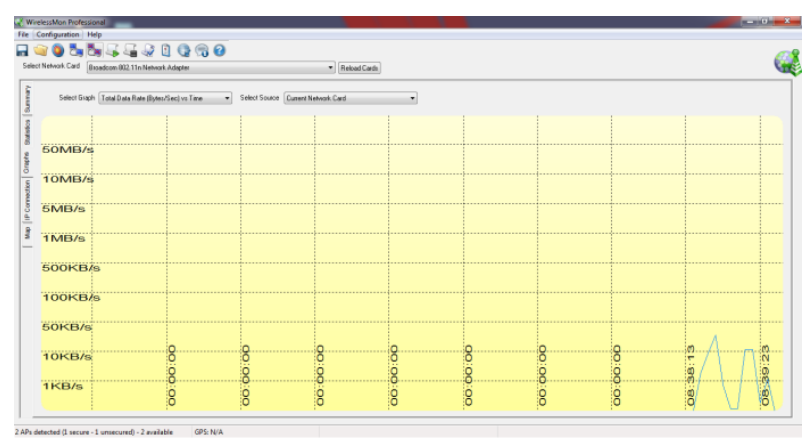

Gambar 5. Tab Graph ((Total Data Rate [Bytes/Sec] vs Time) $0 \mathrm{~m}-3 \mathrm{~m}$ )

2) Pengujian sinyal wirelles pada jarak $3 m-5 m$

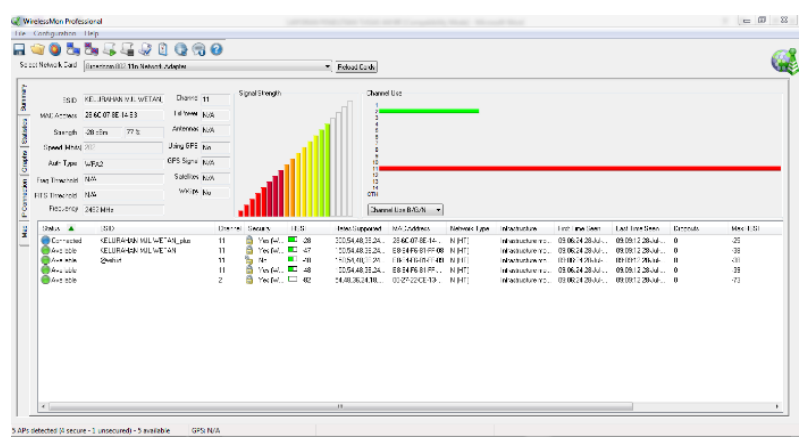

Gambar 6. Tab Summary (3m-5m)

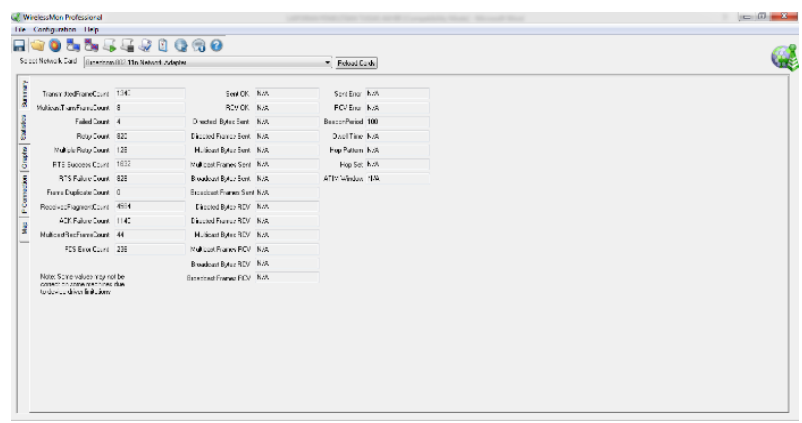

Gambar 7. Tab Static (3m-5m)

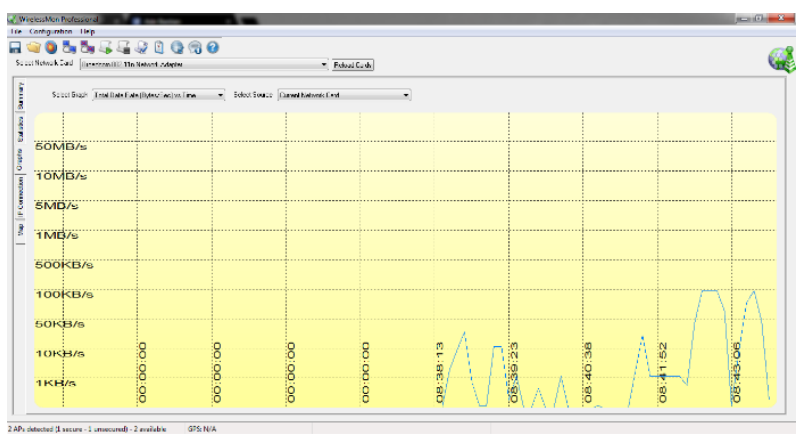

Gambar 8. Tab Graph ((Total Data Rate [Bytes/Sec] vs Time)3m-5m)

3) Pengujian sinyal wirelles pada jarak 5m-6m

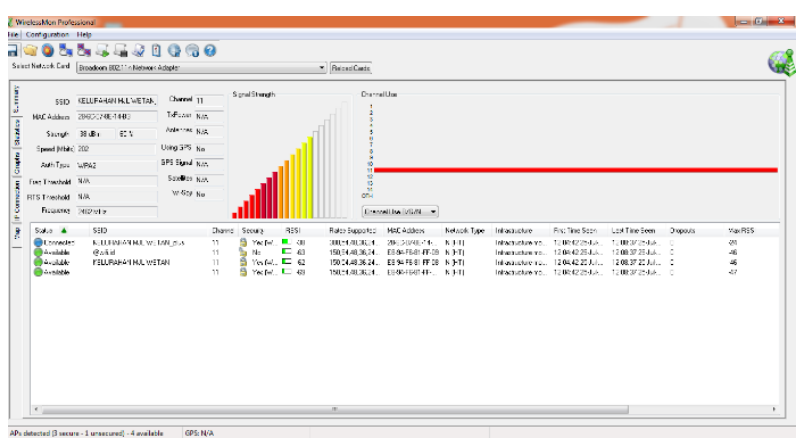

Gambar 9. Tab Summary (5m-6m)

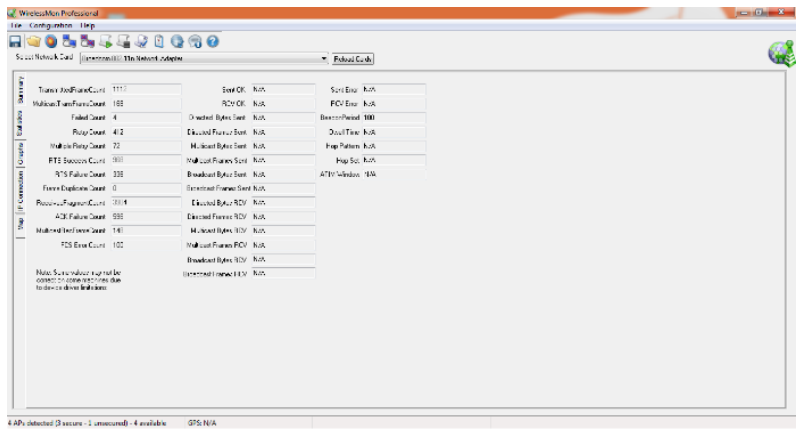

Gambar 10. Tab Static (5m-6m) 


\section{(2) UTama}

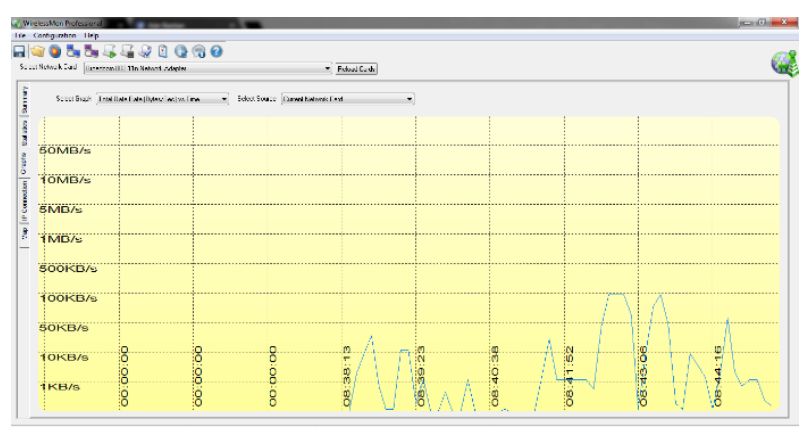

Gambar 11. Tab Graph (Total Data Rate [Bytes/Sec] vs Time)5m-6m)

4) Pengujian sinyal wirelles pada jarak $6 \mathrm{~m}-7 \mathrm{~m}$

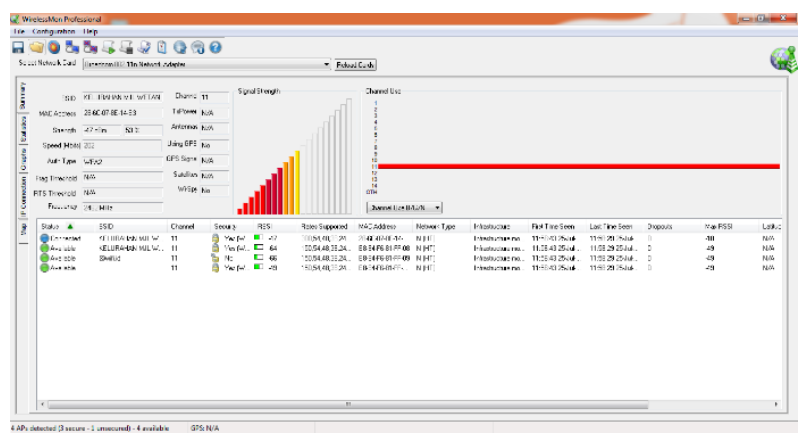

Gambar 12. Tab Summary (6m-7m)

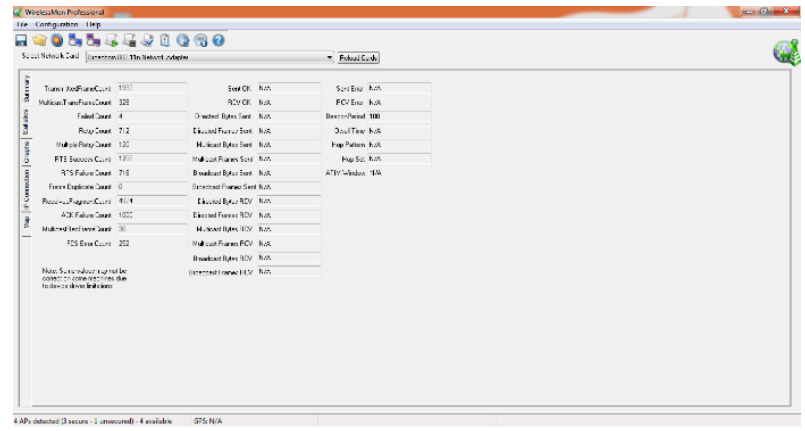

Gambar 13. Tab Static (6m-7m)

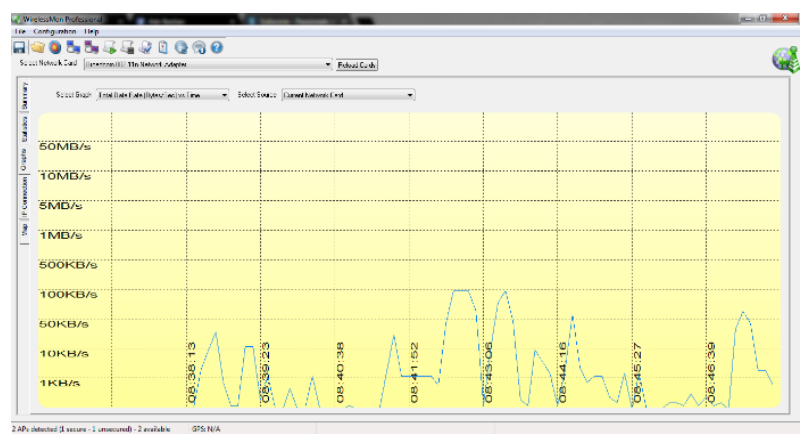

Gambar 14. Tab Graph ((Total Data Rate [Bytes/Sec] vs Time)6m-7m)

5) Pengujian sinyal wirelles pada jarak $7 m-9 m$

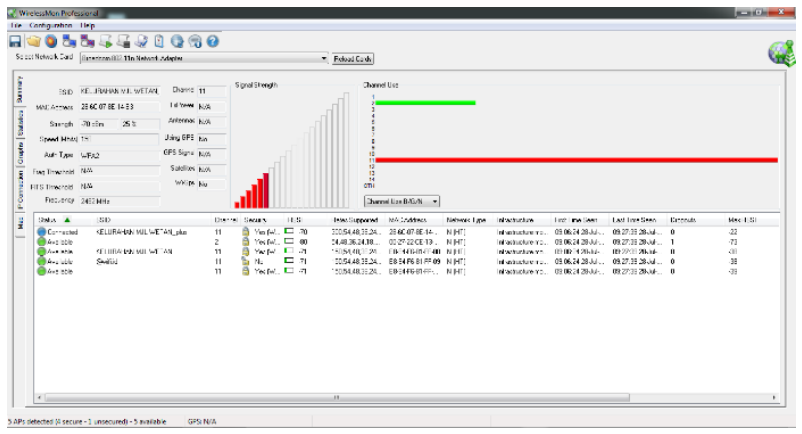

Gambar 15. Tab Summary (7m-9m)

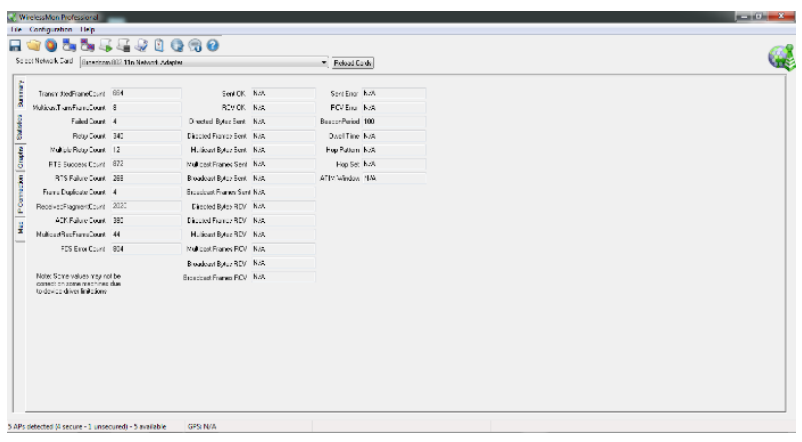

Gambar 16. Tab Static (7m-9m) 


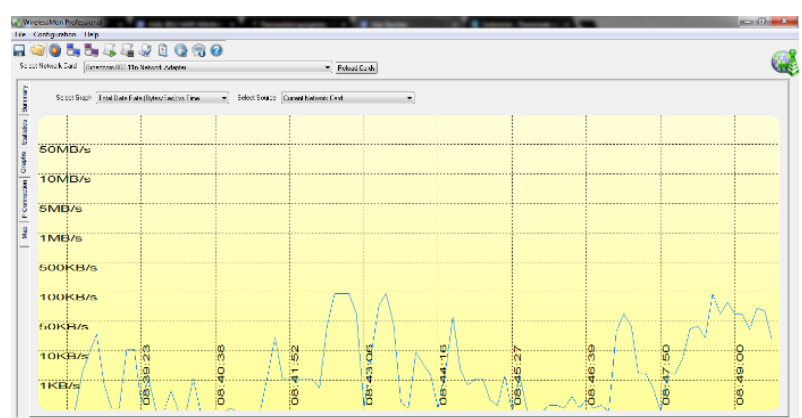

Gambar 17. Tab Graph ((Total Data Rate [Bytes/Sec] vs Time) $7 \mathrm{~m}-9 \mathrm{~m})$

6) Pengujian sinyal wirelles pada jarak $\pm 10 \mathrm{~m}$

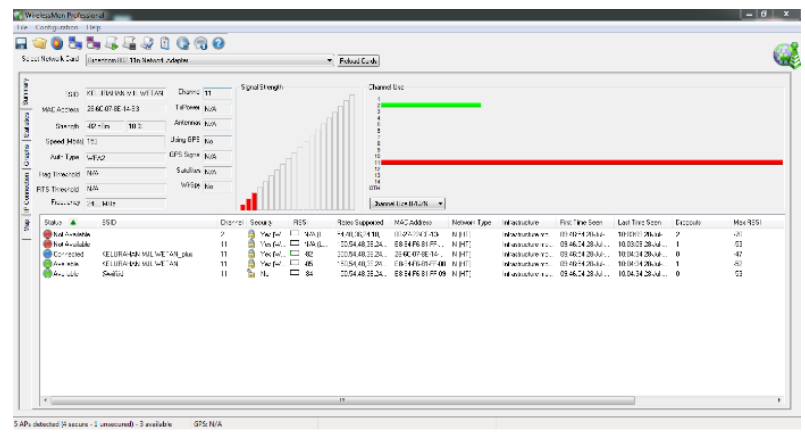

Gambar 18. Tab Summary $( \pm 10 \mathrm{~m})$

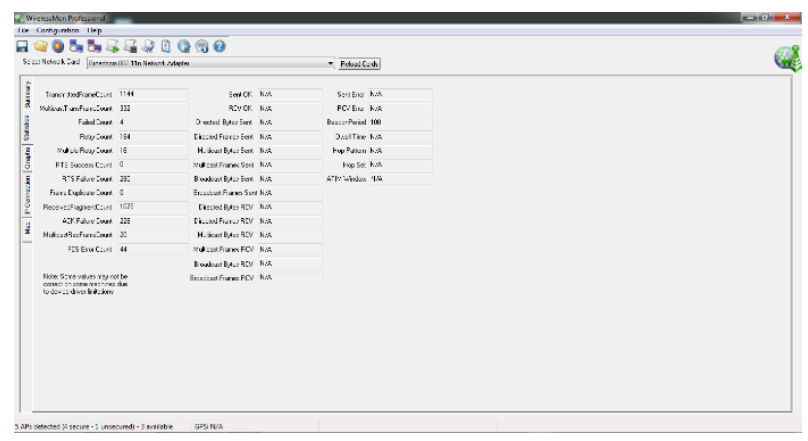

Gambar 19. Tab Static $( \pm 10 \mathrm{~m})$

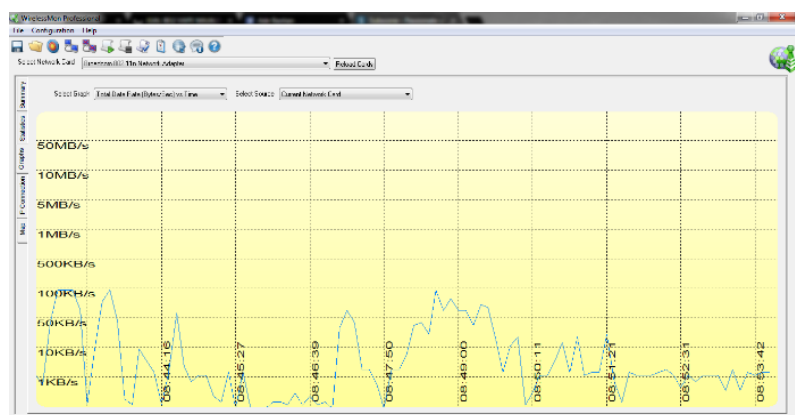

Gambar 20. Tab Graph ((Total Data Rate [Bytes/Sec] vs Time) $\pm 10 \mathrm{~m})$

\section{KESIMPULAN DAN SARAN}

\section{V.1 Kesimpulan}

Beberapa kesimpulan dari rumusan masalah diatas adalah sebagai berikut :

1. Meningkatkan jarak lingkup sinyal wirelles dilakukan dengan cara pengambungan antara repeater dengan bahan bekas layak pakai sehingga tercipta piranti jaringan repeater eco village.

2. Bahan dalam perakitan piranti jaringan repeater disesuaikan dengan kebutuhan sistem yang ada.

3. Piranti karingan repeater yang dibuat dapat disesuaikan arah sinyalnya oleh pengguna sehingga memungkinkan alur pertukaran data lancar.

\section{V.2 Saran}

Kedepannya dalam melakukan pengemangan penelitian mengenai piranti jaringan repeater diharapkan dapat lebih baik lagi dari segi bentuk repeater serta fungsi yang dimilikinya dapat dikembangkan lagi, beberapa yang perlu diperhatikan dalam pengembangan sistem kedepan adalah sebagai berikut :

1. Bahan paralon yang digunakan diganti dengan bahan stainless steel yang bagus dalam mengantarkan sinyal wireless.

2. Gunakan antena extender dalam perakitannya, sehingga dapat menjadi salah satu faktor tambah dalam memperluas jangkauan sinyal pada repeater. 
3. Diperluas lagi cakupan objek penelitiannya sehingga manfaat dari piranti ini dapat lebih dirasakan.

4. Perhartikan juga kebutuhan sistem pada objek penelitian, sesuaikan dengan piranti jaringan yang akan dibuat.

\section{Daftar Pustaka}

Ardiyansyah, F. (2016, Mei 5). Pengertian Repeater Nirkabel. Diambil kembali dari https://perangkatkeraskomputerblog.wordp ress.com/2016/05/05/pengertian-repeaternirkabel/

Novita, I. (2013, Juni 1). Pentingnya Pemanfaatan Daur Ulang. Diambil kembali dari https://vartikel.com/6838/pentingnyamanfaat-daur-ulang-sampah/

Pramono, J. (2008). Pengertian, Fungsi dan Manfaat Internet yang Perlu Anda Ketahui. Diambil kembali dari http://www.nesabamedia.com/pengertianfungsi-dan-manfaat-internet-lengkap/: http://www.nesabamedia.com

Sasrawan, H. (2016). Makalah Pemanfaatan Barang Bekas. Dipetik April 26, 2017, dari http://www.warnetgadis.com/2016/01/vbehaviorurldefaultvmlo.html

Murugesan, San. (2008). Harnessing Green IT : Principles. pp 24-33. Wiley, United Kingdom.

Pressman, Roger S. (2008). Software Engineering. McGraw-Hill, America. 